\title{
Misleading Radiological Appearances for Fever of Unknown Origin: Beyond Terminal Ileitis
}

\author{
Nedeni Bilinmeyen Ateşte Yanıltıcı Radyolojik Görünümler: Terminal Ileitin Ötesinde
}

\author{
(D) Ahmet Naci EMECEN ${ }^{1}$, (D) Burcu IŞIK ${ }^{1}$, (D) Ahmet ASLAN², (D) Ferhat ARSLAN ${ }^{1}$, (D) Haluk VAHABOĞLU ${ }^{1}$ \\ ${ }^{1}$ istanbul Medeniyet University Faculty of Medicine, Department of Infectious Diseases and Clinical Microbiology, Istanbul, Turkey \\ ${ }^{2}$ istanbul Medeniyet University Faculty of Medicine, Department of Radiology, Istanbul, Turkey
}

Keywords: Terminal ileitis, giant cell arteritis, fever of unknown origin, NSAIDs

Anahtar Kelimeler: Terminal ileit, dev hücreli arterit, nedeni bilinmeyen ateş, NSAii

\section{Dear Editor,}

Fever of unknown origin (FUO) diagnosis and treatment presents a challenge to clinicians. Infections, malignancies and collagen vascular diseases are the most common etiologies of FUO ${ }^{[1]}$. Patient history, physical examination, imaging methods and invasive procedures are the steps to diagnosis. Improved radiological and nuclear techniques may provide important clues for diagnosis ${ }^{[2]}$. Nevertheless, a reappraisal of the patient history and repetition of the physical examination may prevent unnecessary interventions. Especially, autoimmune and autoinflammatory processes could be misleading when they conclude without a medical history.

Patients with prolonged fever and myalgia may use non-steroidal anti-inflammatory drugs (NSAIDs) to relieve symptoms. Nonsteroidal anti-inflammatory drugs may cause small intestine damage in addition to well recognized gastrointestinal side effects, such as acute erosive gastritis and duodenal ulcer $^{[3]}$. Especially in the case of terminal ileum involvement, the clinician may focus on the FUO causes like malignancies, Crohn's disease, and tuberculosis ${ }^{[4]}$.

Herein, we report two cases of confirmed giant cell arteritis (GCA) which were complicated with small intestinal damage associated with prolonged NSAIDs use that mislead the clinicians to other FU0 etiologies.

A 61-year-old man with the history of diabetes mellitus was admitted to our clinic with fever, night sweats, weight loss, weakness and headache lasted for four months. In that period, he had multiple, exhausting hospital admissions and various NSAIDs (especially diclofenac sodium) were prescribed for fever and headache. His physical examination was normal on admission. His white blood count (WBC) was 10100/mm ${ }^{3}$, hemoglobin level was $8.8 \mathrm{~g} / \mathrm{dL}, \mathrm{C}$-reactive protein (CRP) was $19.5 \mathrm{mg} / \mathrm{dL}(0-0.5 \mathrm{mg} / \mathrm{dL})$, and erythrocyte sedimentation rate (ESR) was $56 \mathrm{~mm} /$ hour. Blood cultures yielded no growth of any microorganism. The fecal occult blood test was positive. On computed tomography (CT), the terminal ileum wall was thickened (Figure 1a). Tuberculin skin test was anergic and T-SPOT.TB test (Oxford Immunotech, Oxford, United Kingdom) was positive. Empiric anti-tuberculosis therapy was initiated with the preliminary diagnosis of gastrointestinal system tuberculosis but his fever continued during anti-tuberculosis treatment. Positron emission tomography/CT (PET/CT) was performed to detect occult malignancy. Positron emission tomography/CT revealed thickening and intense hypermetabolic involvement of the ileocaecal wall. An ulcerated lesion was seen on colonoscopy and biopsies were taken. On pathologic examination of the specimen, there was ongoing lymphoplasmacytic infiltration of the muscularis mucosa, granulation tissue and lymphoid follicle on the ulcer base. No evidence of tuberculosis was found by histopathological examination. His headache was worsened and his vision was blurred. The temporal artery biopsy was consistent with arteritis and, methylprednisolone $(1 \mathrm{mg} / \mathrm{kg})$ was started. Latent tuberculosis treatment with isoniazid $300 \mathrm{mg}$ continued 
for six months. The patient was discharged with a clinical and laboratory improvement. After one year of follow-up, his general condition went well and symptoms did not recur.

The second case was a 62-year-old man presented with fever, night sweats, myalgia, and anorexia for two weeks. He had been diagnosed with osteoarthritis two years ago and received NSAIDs (dexketoprofen trometamol) for pain management. His physical examination was normal on admission. In the laboratory investigation, WBC was $31000 / \mathrm{mm}^{3}$ (neutrophilic leukocytosis), hemoglobin was $9.7 \mathrm{~g} / \mathrm{dL}$, CRP was $34 \mathrm{mg} / \mathrm{dL}$ (0$0.5 \mathrm{mg} / \mathrm{dL}$ ), and ESR was $96 \mathrm{~mm} /$ hour. Tuberculin skin test was anergic. Blood cultures were negative. Abdominal tomography revealed diffuse thickening of the cecum and terminal ileum (Figure 1b). Multiple aphthous ulcers were observed in the terminal ileum on colonoscopy and chronic active non-specific inflammation was defined in terminal ileum biopsy. Polymerase chain reaction (Qiagen, Hilden, Germany) of the sample for Mycobacterium tuberculosis complex DNA was negative. Despite hospitalization over a week, his fever continued. On the $9^{\text {th }}$ day of hospitalization, blurred vision occurred in the right eye for 15 minutes. Methylprednisolone $(1 \mathrm{mg} / \mathrm{kg}$ ) was started immediately in consideration of temporal arteritis. On the $13^{\text {th }}$ day, lesions of purple coloured macules appeared in both toe tips and soles which were evaluated as vasculitic lesions. The patient, who was clinically responsive to methylprednisolone, was followed up for ten months without any complication.

Giant cell arteritis is chronic vasculitis of large and mediumsized vessels. Giant cell arteritis prevalence increases with age especially among individuals older than 50 years. Diagnosis is made with the combination of symptoms, laboratory, imaging methods and invasive procedures ${ }^{[5]}$. Typical clinical manifestations are unexplained fever, headache, jaw claudication, scalp tenderness, and visual disturbances. Some patients may present with symptoms of polymyalgia rheumatica such as diffuse myalgia ${ }^{[5,6]}$. Pathology confirmed GCA in our first patient. In the second patient, sudden development of visual loss on the course of long-lasting fever and polymyalgia has alerted us for GCA. After immediate methylprednisolone therapy, we observed clinical and laboratory response. Our rheumatologist concluded that the patient had GCA according to the clinical and laboratory findings because the patient refused to undergo biopsy after clinical recovery.

Unexplained long-lasting fever and myalgia may lead to NSAIDs use while the preclinical and clinical evaluation of GCA is ongoing. While clinicians are investigating long-lasting fever, CT and PET/CT scanning may be beneficial in establishing the diagnosis of $\mathrm{GCA}^{[7]}$. False-positive results of these tests, which can lead to unnecessary investigations and interventions, are a challenge. Our patients were investigated with CT and PET/ CT scanning before taking comprehensive patient history. Nonsteroidal anti-inflammatory drugs use of the patients was overlooked at the first evaluation. Terminal ileum involvement misled us to other possible causes related with FUO.

Terminal ileum involvement is related to many diseases such as inflammatory bowel disease, malignancy, vascular ischemia, spondyloarthropathies, infiltrative diseases and drug intake ${ }^{[4,8]}$. Non-steroidal anti-inflammatory drug use seems to be associated with erosions, ulcers, strictures, perforations and diaphragms leading to obstructions of the ileocaecal region ${ }^{[3,9]}$. This risk is higher in elderly patients and long-term NSAID users. Mucosal abnormalities may be seen even in healthy individuals $^{[10]}$. Thus, NSAID use should be questioned in case of terminal ileum involvement.
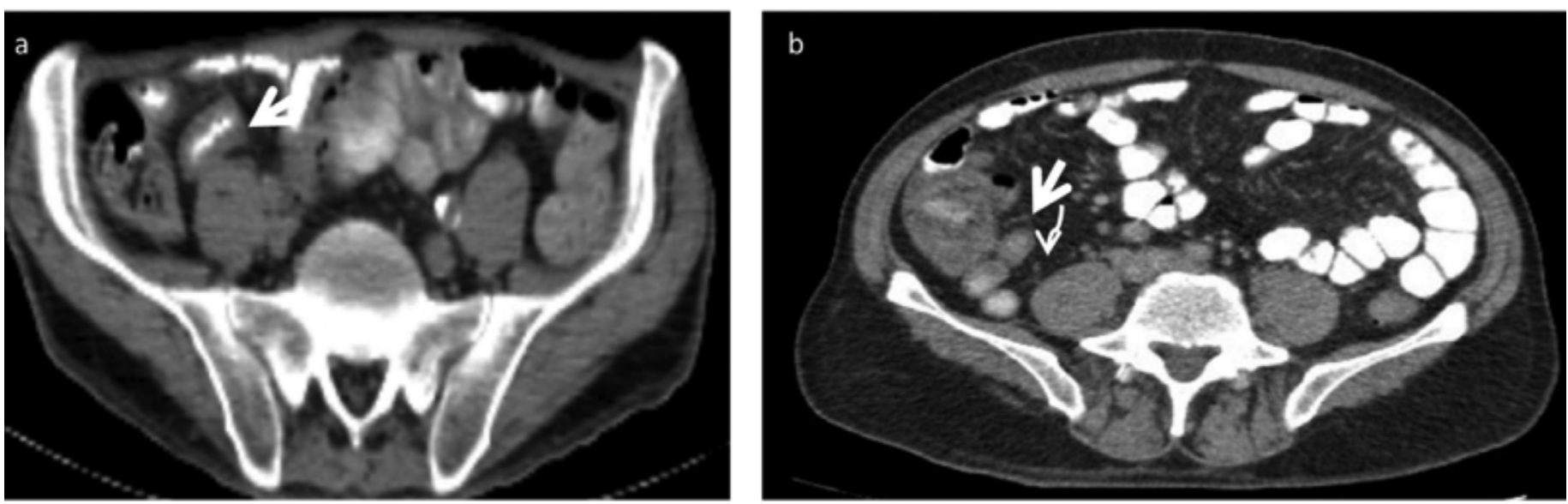

Figure 1. a) The wall of terminal ileum was thickened on axial oral contrast enhanced computed tomographic image (arrow). The lumen permits intestinal passage. b) On axial intravenous and oral contrast enhanced computed tomography, the wall of terminal ileum is thickened (arrow). There is also lineer hyperdensities at mesenteric fat (curved arrow) 
In conclusion, defining the symptoms correctly, careful history taking and detailed physical examination should be the first step while investigating FUO. In recent years, the presence of advanced imaging methods and invasive procedures is pushing doctors' skills of clinical evaluation to background. Assessment of the patient history without being influenced by imaging methods is the most important parameter to the diagnosis.

\section{Ethics}

Peer-review: Externally and internally peer-reviewed.

\section{Authorship Contributions}

Surgical and Medical Practices: A.E., B.I., A.A., Concept: F.A. Design: F.A., A.A., Data Collection or Processing: A.E., B.I., F.A., Analysis or Interpretation: H.V., Literature Search: A.E., B.I., Writing: A.E., F.A.

Conflict of Interest: No conflict of interest was declared by the authors.

Financial Disclosure: The authors declared that this study received no financial support.

\section{References}

1. Sipahi OR, Senol S, Arsu G, Pullukcu H, Tasbakan M, Yamazhan T, Arda B, Ulusoy S. Pooled analysis of 857 published adult fever of unknown origin cases in Turkey between 1990-2006. Med Sci Monit. 2007;13:318-22.

2. Pereira $A M$, Husmann L, Sah BR, Battegay E, Franzen D. Determinants of diagnostic performance of 18F-FDG PET/CT in patients with fever of unknown origin. Nucl Med Commun. 2016;37:57-65.

3. Lim YJ, Yang $\mathrm{CH}$. Non-steroidal anti-inflammatory drug-induced enteropathy. Clin Endosc. 2012;45:138-44.

4. Dilauro S, Crum-Cianflone NF. Ileitis: when it is not Crohn's disease. Curr Gastroenterol Rep. 2010;12:249-58.

5. Buttgereit F, Dejaco C, Matteson EL, Dasgupta B. Polymyalgia Rheumatica and Giant Cell Arteritis: A Systematic Review. JAMA. 2016;315:2442-58.

6. González-Gay MA, Pina T. Giant cell arteritis and polymyalgia rheumatica: an update. Curr Rheumatol Rep. 2015;17:6.

7. Lariviere D, Benali K, Coustet B, Pasi N, Hyafil F, Klein I, Chauchard M, Alexandra JF, Goulenok T, Dossier A, Dieude P, Papo T, Sacre K. Positron emission tomography and computed tomography angiography for the diagnosis of giant cell arteritis. Medicine (Baltimore). 2016;95:e4146.

8. Goulart RA, Barbalho SM, Gasparini RG, de Carvalho AC. Facing Terminal Ileitis: Going Beyond Crohn's Disease. Gastroenterology Res. 2016;9:1-9.

9. Bojic D, Markovic S. Terminal ileitis is not always Crohn's disease. Ann Gastroenterol. 2011;24:271-5.

10. Maiden L, Thjodleifsson B, Theodors A, Gonzalez J, Bjarnason I. A quantitative analysis of NSAID-induced small bowel pathology by capsule enteroscopy. Gastroenterology. 2005;128:1172-8. 